\title{
O PAPEL DA CONFIANÇA NA CONCESSÃO DE CRÉDITO PARA EMPRESAS EM RECUPERAÇÃO
}

\author{
THE ROLE OF CONFIDENCE IN CREDIT CONCESSION \\ FOR COMPANIES IN ECONOMIC-FINANCIAL RECOVERY
}

\author{
ROGÉRIO SILVEIRA MONTEIRO \\ Mestre em Administração pela Universidade Presbiteriana Mackenzie (UPM). \\ Avenida Leandro Dupret, 364, compl. 62, Vila Clementino - São Paulo - SP - CEP 04025-01 1 \\ E-mail: mont@uol.com.br
}

MARIA LUISA MIENDES TEIXEIRA

Doutora em Administração pela Universidade de São Paulo (USP). Professora adjunta 3 do Centro de Ciências Sociais e Aplicadas da Universidade Presbiteriana Mackenzie (UPM). Rua da Consolação, 930, Consolação - São Paulo - SP - CEP $01302-907$ E-mail: mallu@mackenzie.br 


\section{RESUMO}

A incerteza, a complexidade e o risco do ambiente organizacional tornam-se mais intensos em empresas que estejam em situações de crise financeira. As relações entre empresas credoras e devedoras passam a responder a mecanismos, jurídicos ou não, que buscam atender às expectativas dos stakehoders envolvidos. Assim, pode-se esperar que as empresas em crise estabeleçam planos de recuperação financeira que poderão ter apoio dos credores envolvidos. O constructo Confiança é apresentado na literatura como fonte de redução das incertezas, da complexidade e dos riscos. O objetivo desta pesquisa consistiu em compreender a predisposição dos gestores de empresas credoras a confiar em empresas em recuperação financeira tendo em vista a concessão de créditos financeiros. A pesquisa, qualitativa, teve os dados coletados mediante entrevistas; examinando-os por meio da análise de domínio. Os resultados identificaram que a predisposição a confiar - tendo em vista a concessão de créditos - é decorrente dos atributos da empresa em recuperação financeira e de seu gestor, os quais são identificados por meios não convencionais.

\section{PALAVRAS-CHAVE}

Confiança; Recuperação financeira; Análise de domínio; Risco; Concessão de crédito.

\section{ABSTRACT}

The uncertainty, complexity and risk of the organizational environment become more intense in a scenario in which companies face a situation of financial crisis. The relation between creditor and debtor companies begin to respond to juridical or non-juridical mechanisms that aim to reach the expectations of the stakeholders. Thus, it can be expected that companies in crisis establish plans of economic-financial recovery that may or may not be supported by the 
involved stakeholders. The concept of Trust is described in the literature as a source of reduction of uncertainties, complexity and risks. The general objective of this research is to understand the predisposition of the managers to believe in companies under financial recovery. The data of the qualitative research was collected through interviews and were analyzed by the domain analysis. The results shown that credit concession is generated by the confidence created through the perceived attributes of the company in economic-financial recovery and its manager, which are identified by non-conventional techniques.

\section{KEYWORDS}

Trust; Financial recovery; Domain analysis; Risk; Credit concession.

\section{INTRODUÇ ÃO}

O risco, a incerteza e a complexidade são características do modelo econômico, político e social iniciado a partir da era pós-industrial (DE MASI, 2000; CASTELLS, I999; NAHM; VONDEREMBSE, 2002) e a minimização de seus impactos passaram a ser contemplados na formulação das estratégias das organizações.

Os impactos provocados pelas incertezas, complexidades e risco intensificaram-se, entretanto, no momento em que uma organização entra em dificuldades financeiras, chegando a uma etapa pré-falimentar ou em recuperação judicial - processo que atualmente substitui a concordata.

É intrigante pensar sob quais aspectos são sedimentadas as relações entre empresas credoras e devedoras, especialmente quando essas atingiram um patamar elevado de incapacidade de cumprimento dos seus compromissos, encontrando-se em uma situação em que já não possuem garantias reais para oferecer em troca de novos recursos financeiros. Supõe-se que, nesses casos, os mecanismos convencionais de avaliação de crédito não sejam, por si só, os mais adequados e que a avaliação dos gestores credores para a concessão de crédito para empresas em recuperação financeira (ERF) assuma um caráter mais subjetivo.

Nessas situações, percebe-se que as relações entre as empresas tornam-se permeadas por uma dose maior de riscos. Tendo em vista que Luhmann (I996) vê a confiança como aquela capaz de atuar na redução dos riscos e incertezas, pode-se, então, pressupor que as transações entre as empresas credoras e em recuperação financeira são efetivadas pelos gestores credores que pensam, sen- 
tem e decidem por meio do dimensionamento das suas expectativas futuras. Ao confiarem na recuperação de uma empresa, esses gestores demonstram sua disposição por assumirem riscos, pressupondo uma escolha entre várias alternativas fundamentadas em relações de confiança.

A confiança pode ser entendida como um estado subjetivo inerente às expectativas positivas em relação ao outro (DAS; TENG, 200I; McALLISTER, I995; MAYER; DAVIS; SHOORMAN, I995). No caso das ERF, o estado subjetivo do gestor credor quanto às expectativas positivas em relação ao cumprimento dos acordos estabelecidos envolve duas proposições: em quem confiar e como confiar.

Sob a óptica da primeira proposição, a confiança é uma função decorrente dos atributos percebidos pelo credor em relação à ERF e seu gestor; a segunda proposição fundamenta-se na forma cognitiva e afetiva sob a qual a confiança é estabelecida.

Nesse sentido, este trabalho tem como objetivo compreender a predisposição dos gestores de empresas credoras a confiar em ERF no que tange à concessão de créditos financeiros destinados a essas empresas.

Para atender a essa expectativa, o texto foi organizado em quatro partes. $\mathrm{Na}$ primeira, analisam-se as diversas abordagens em relação ao conceito Confiança; na segunda, discorre-se sobre o método de pesquisa utilizado; na terceira, apresentam-se os resultados e as interpretações encontradas e, finalmente, as conclusões do trabalho.

\section{REFERENCIAL TEÓRICO}

Após muitos anos de tramitação no congresso brasileiro, a nova lei de falência (Lei n. II.IOI/2005) foi promulgada com o objetivo geral de facilitar que as empresas em dificuldades financeiras retomem a normalidade operacional dentro do ambiente competitivo em que estão inseridas. Como destaca Astrauskas (2003), beneficiam-se dessa possibilidade os agentes diretamente ligados à organização, tais como controladores, colaboradores e credores, como também a sociedade em geral, uma vez que ela procura atender aos interesses coletivos, tais como oportunidade de trabalho, estabilidade econômica e a garantia de um fluxo econômico-financeiro equilibrado.

Dentre as várias alterações implementadas nessa nova lei, destaca-se a substituição da entidade jurídica "Empresa em Concordata" pela entidade "Empresa em Recuperação Judicial ou Extrajudicial”, a qual assume o compromisso legal da elaboração e da implementação de um plano de recuperação judicial (PRJ) perante todos os envolvidos nessa recuperação (ou nesse processo). Esse plano 
apresentará as estratégias e o prazo para recuperá-las, bem como será avaliado e supervisionado por uma comissão de credores, de trabalhadores e de representantes da empresa: o Comitê de Recuperação.

É importante ressaltar, no entanto, que no PRJ devem estar contempladas não só as necessidades da empresa solicitante, como também as de todos os stakeholders envolvidos em sua recuperação. Nesse momento, o plano deixa de ser apenas um instrumento jurídico, uma estratégia de atuação ou um simples plano de negócios de uma organização, e assume uma perspectiva mais ampla, buscando uma coalizão de interesses para alcançar o seu fim (MONTEIRO, 2005; 2006).

Quando se fala nas expectativas das instituições envolvidas, não se pode deixar de levar em conta que a percepção do risco, os níveis de incertezas e a complexidade do ambiente organizacional em uma situação de recuperação financeira intensificam-se.

Assim sendo, a busca de alianças estratégicas que ajudem a superar os desafios que envolvem crescimento organizacional é permeada pela qualidade da confiança nas relações entre as partes envolvidas (SHEPPARD, I995). A confiança é entendida como um elemento que reduz a existência do risco, das incertezas e da complexidade do ambiente, minimizando seus impactos por meio do dimensionamento das expectativas futuras dos relacionamentos interpessoais, intergrupais e institucionais. Portanto, confiar não é tomar o risco por si, mas sim a disposição para assumir riscos (MAYER; DAVIS; SCHOORMAN, I995), pressupondo uma escolha entre várias opções (LUHMANN, I988).

Para tanto, uma das estratégias para a redução da complexidade e do risco é a projeção racional. Essa estratégia baseia-se nas Teorias Racionais, Teorias de Jogos ou na Teoria de Custos de Transação, cuja fundamentação está em dois atributos dos agentes econômicos: oportunismo e racionalidade limitada. Williamson (I993) define o oportunismo como a busca pelo atendimento dos interesses próprios, enquanto a racionalidade limitada é definida como o fato de todo agente econômico ser racional e de essa racionalidade possuir limites. Outra estratégia para a redução da complexidade e do risco se dá pela capacidade de se calcular o comportamento futuro do agente econômico (GAMBETTA, I988; WILLIAMSON, I993; LEWIS; WEIGERT, I985; BACHMANN, 200I). Nesse aspecto, é mediante a coleta e o processamento de informações que se (ou eles) preveem que um determinado acontecimento possui grande probabilidade de ocorrer, permitindo-se traçar planos para o presente.

Dessa forma, os agentes econômicos calculam, antes de tomarem qualquer decisão, os ganhos ou perdas resultantes da decisão de confiar ou não em outro agente econômico. Trata-se de uma interpretação em termos de eficiência e de 
credibilidade. A relação entre os agentes passa, então, a ser monitorada por "instrumentos de governança”, tais como contratos, leis, normas, e outros (WILLIAMSON, I993).

Lewis e Weigert (I985), Bachmann (200I) e Luhmann (I996), pesquisadores da abordagem sociológica do constructo Confiança, afirmam, entretanto, que o planejamento racional não é suficiente para a redução da complexidade, pois não há tempo nem recursos para racionalizar as projeções e controlar os resultados. A ignorância ou as incertezas quanto ao comportamento do outro estão relacionadas com o limite de nossa capacidade de alcançar o pleno conhecimento sobre eles, seus motivos e suas respostas para as mudanças endógenas ou exógenas (GAMBETTA, I988).

A incerteza aparece como algo não mensurável (KNIGHT, 2002), ou ainda como a dificuldade da capacidade psicológica que um ator social tem em lidar com as inúmeras possibilidades de ação (ou reação) do mundo, o que gera uma maior complexidade de coordenação e interação (LUHMANN, I988).

A relação entre os agentes sociais é permeada por uma grande dose de "dúvida potencial” (LEWIS; WEIGERT, I985) em relação ao seu comportamento futuro. Para Bachmann (200I), o comportamento futuro dos outros agentes sociais com os quais se quer interagir é completamente contingencial, existindo ilimitadas possibilidades de ações e reações que excedem sua capacidade psicológica de selecionar as desejáveis ou indesejáveis. Assim, o mundo aparenta ser incerto e muito complexo para a coordenação das expectativas e para a interação entre os agentes.

A complexidade é reconhecida, segundo Lewis e Weigert (I985), como um efeito temporal da vida social. A interação social define o início e o fim de cada atividade. A redução da complexidade se dá à medida que a probabilidade de $o$ outro agente social agir de forma diferente àquela esperada tender a zero.

Para a abordagem sociológica, a redução da complexidade e das incertezas do ambiente se dá por meio da construção de um sistema social menos complexo do que o ambiente. Para Luhmann (I988), essa redução da complexidade é essencial à vida social e sem ela o mundo seria nada - não existiriam agentes sociais, mas apenas o indiferente caos.

A habilidade dos agentes sociais em criar condições para a redução da complexidade passa a exercer uma função próxima à de um mecanismo de proteção à vida social e implica, portanto, uma seleção entre diversas possibilidades. Nesse processo de seleção, a escolha pressupõe uma aceitação racional do risco.

Luhmann (I988) define o risco como o resultado não esperado das decisões. Para ele, o risco emerge como um componente da decisão e da ação e age como um cálculo interno em relação às condições externas. A ação se fundamenta em um potencial risco externo e, ao mesmo tempo, o risco existe quando o ator social, mesmo 
conhecendo a possibilidade de ter consequências indesejadas, decide por uma ação. Dessa forma, a distinção crucial entre o risco e a incerteza torna-se evidenciada, pois o primeiro é mensurável, enquanto o segundo é não-mensurável (KNIGHT, 2002).

Esse risco é reconhecido como um traço inevitável da confiança: aquele que confia, tenta constantemente achar uma "boa razão" para acreditar que o risco que ele está disposto a assumir é baixo. Somente quando o agente social encontra essa "boa razão" é que a confiança assume o controle das interações sociais entre indivíduos ou organizações (BACHMANN, 200I).

Luhmann (1996) vê a confiança como aquela que atua na solução da coordenação e interação entre os agentes sociais quanto às expectativas futuras de seus comportamentos, pois é capaz de reduzir as incertezas ao assumir específicas suposições sobre o comportamento futuro dos outros agentes sociais. O relacionamento entre os agentes sociais ocorre sustentado pela suposição de que o outro não agirá de forma oportunística em relação àquele em quem confia. Não há a necessidade de nenhum tipo de garantia concreta (como sugere a Teoria dos Jogos ou a Teoria dos Custos de Transação), já que, se houvesse, a interação não seria sustentada por uma relação de confiança.

Para que a confiança tenha relevância, os agentes sociais devem atuar de forma livre, ou seja, se as ações dos agentes sociais forem restritas ou controladas, o papel da confiança no governo das decisões passa a ser pequeno, haja vista que os limites das ações são mais previsíveis. Assim sendo, a liberdade mencionada por Gambetta (I988) está relacionada à capacidade de um agente social agir de forma livre no sentido de desapontar o outro. Por conseguinte, o risco do relacionamento torna-se evidente e a confiança surge como elemento que auxilia na decisão de acreditar ou não no comportamento do outro.

A confiança reduz a complexidade e as incertezas, já que age de forma mais rápida, econômica e completa, permitindo a interação social sob uma base simples e confiante.

Do mesmo ponto de vista, a confiança pode ser definida como as expectativas positivas relativas ao comportamento do outro (LEWICKI; MCALLISTER; BIES, I998; DAS; TENG, 200I); nesse sentido, pode ser considerada uma propriedade de unidades coletivas (LEWIS; WEIGERT, I985) que pressupõe uma escolha entre várias alternativas (LUHMANN, I988), revelando a disposição por assumir risco (MAYER; DAVIS; SCHOORMAN, I995).

Tendo como pressuposto que, neste trabalho, a relação de confiança estudada é aquela que ocorre entre agentes sociais - o gestor credor e o gestor de ERF -, a confiança foi considerada uma predisposição dos primeiros a agir de acordo com as situações e o contexto social em que se inserem ante expectativas positivas relativas aos segundos. Os gestores credores são aqui compreendidos 
fazendo parte de unidades coletivas na medida em que expressam a cultura de uma categoria de profissionais.

A confiança no âmbito das organizações pode ser compreendida sob as perspectivas intraorganizacional e interorganizacional. McAllister (I995), ao considerar a relação entre os pares, aborda a confiança da perspectiva intraorganizacional, mencionando que essa perspectiva possui duas dimensões: a cognitiva e a afetiva. A dimensão cognitiva, de natureza racional, é formada a partir de elementos externos ao indivíduo, ao passo que a dimensão afetiva baseia-se nos elementos internos (insights).

A dimensão cognitiva da confiança, segundo o autor, fundamenta-se nas boas razões que dão evidências para se confiar. Para o autor, a quantidade de conhecimento necessário para se confiar é algo entre o conhecimento total e a ignorância total. Se existir um conhecimento total, a confiança não se faz necessária, e, na ignorância total, não se tem base suficiente para uma escolha racional. O nível suficiente de conhecimento e as boas razões são as bases fundamentais para se estabelecer a confiança cognitiva.

Segundo McAllister (I995), a construção da confiança cognitiva depende de três elementos antecessores:

a. sucesso da performance dos pares: está relacionado ao reconhecimento da trajetória profissional do par e das evidências do seu comportamento consistente, com a presença de normas de reciprocidade e probidade;

b. extensão da similaridade social: presença de características similares, como a etnia;

c. credenciais profissionais: papel formal dos pares na organização e sinais de preparo individual e outras características reconhecidas na comunidade profissional.

Já a dimensão afetiva da confiança baseia-se nos laços emocionais entre os indivíduos. Segundo McAllister (I995), as pessoas fazem investimentos emocionais no relacionamento de confiança, demonstram cuidados genuínos em relação ao seu par, acreditam na virtude intrínseca desse tipo de relacionamento e creem que esses sentimentos são recíprocos. Nesses aspectos, a confiança afetiva pode ser entendida como voltada à integridade e à responsabilidade dos pares.

Da mesma maneira que os elementos externos auxiliam a construção da confiança cognitiva, os elementos internos estimulam o relacionamento entre pares e constroem os fundamentos para a confiança afetiva. Segundo McAllister (I995), as pesquisas realizadas indicam que o comportamento voltado para o reconhecimento das necessidades legítimas e a demonstração de um cuidado e 
de uma preocupação interpessoal acima dos interesses próprios são elementos que fortalecem a construção de um relacionamento baseado na confiança afetiva entre os pares de uma organização. Esses elementos podem ser definidos como: a. comportamento de cidadania; b. frequência de interações. Indo além, o autor acrescenta que a construção da confiança entre pares profissionais baseada na afetividade exige um nível de confiança cognitiva, ou seja, as pessoas depositam expectativas afetivas naquelas em que já se tenha um conhecimento prévio. Uma vez positivados os elementos relativos à confiança cognitiva, a confiança afetiva passa a ser vista como uma forma distinta de confiança interpessoal cujos atributos tornam-se permanentemente incorporados e inquestionáveis superando a importância da confiança cognitiva.

Nesse mesmo sentido, Passuello e Souza (2006) observam que os elementos mais subjetivos e pessoais contribuem para o estabelecimento das relações de confiança e, consequentemente, para uma maior disposição ao risco nos processos de tomada de decisão.

Ao abordar a confiança interorganizacional, Das e Teng (200I) também se referem a duas dimensões: uma, baseada na integridade (goodwill trust); e, outra, baseada na competência (competence trust).

A confiança baseada na integridade está localizada na reputação da empresa e trata da "boa fé", das boas intenções e da integridade organizacional. Para os autores, esse tipo de confiança reduz a percepção do comportamento oportunista e contribui para um baixo nível de custos de transação. Como a relação baseada nesse tipo de confiança sugere boas intenções, o relacionamento entre os pares não se focaliza em problemas de cooperação. Entretanto, os autores alertam que a confiança baseada na integridade delineia apenas as intenções para que as coisas funcionem e não delineia a capacidade efetiva de fazê-las acontecer.

Por sua vez, a confiança baseada na competência tem como antecedente a construção de uma reputação alicerçada na competência da organização. Das e Teng (200I) sustentam que a competência está baseada em uma série de recursos e de habilidades da organização que incluem capital, recursos humanos, recursos físicos, poder da marca, tecnologia, entre outros.

A relação entre os gestores credores com as empresas em recuperação financeira, tendo em vista a concessão de crédito, poder-se-ia pensar que fossem afetadas apenas pelas dimensões relativas à confiança interorganizacional apontadas por Das e Teng (200I). No entanto, essa relação se dá entre pessoas: gestores de empresas credoras e gestores de empresas em recuperação financeira, que se tornam pares profissionais. Entende-se, portanto, que a confiança inerente a essas relações caracteriza-se tanto pelas dimensões de integridade e competência (confiança interorganizacional), quanto cognitiva e afetiva, essas propostas por McAllister (I995). 
- O PAPEL DA CONFIANÇA NA CONCESSÃO DE CRÉDITO PARA EMPRESAS EM RECUPERAÇÃO • ROGÉRIO SILVEIRA MONTEIRO • MARIA LUISA MENDES TEIXEIRA

\section{PROCEDIMENTOS METODOLÓGICOS}

Para atender aos objetivos desta pesquisa, optou-se por efetuar um conjunto de entrevistas semiestruturadas, apoiadas em um roteiro de entrevista. O roteiro foi elaborado a fim de estimular o entrevistado a discorrer sobre as bases que o levavam a tomar decisões em favor da concessão de crédito financeiro para empresas que estavam em processo de recuperação financeira.

O tratamento dos dados das entrevistas deu-se pela análise de domínio, seguindo a metodologia proposta por Spradley (I979). Essa opção foi escolhida quando se percebeu, durante as entrevistas, que os gestores de empresas credoras, por não pautarem suas decisões de concessão de crédito apenas em elementos formais, desenvolveram formas de agir que tinham se tornado comuns entre os profissionais entrevistados, entendidas por eles como capazes de gerar conhecimento sobre as ERF. Os conhecimentos gerados possibilitam identificar elementos simbólicos relativos às dimensões de confiança, podendo, ou não, estabelecer ou subsidiar a concessão de créditos financeiros.

Outro aspecto que conduziu a opção por esse tipo de tratamento foi o fato de os entrevistados empregarem termos populares que, para eles, têm um significado específico e foi compartilhado entre eles. Para Spradley (I979), os termos populares (folk terms) são símbolos que criam um significado cultural. Por esses motivos, considerou-se ser a análise de domínio a mais adequada para este trabalho.

Para Spradley (I979), a análise de domínio envolve a identificação das maiores unidades de conhecimento cultural, chamadas domínio, representadas por símbolos que são incluídos em categorias (domínios) por virtude ou similaridade. Domínio é definido como uma simbólica categoria que inclui outras categorias. O primeiro elemento da estrutura do domínio é o cover term. Cover terms são os nomes das categorias de um conhecimento cultural. O segundo elemento da estrutura do domínio destacado por Spradley (I979) é chamado de Included terms. Esses são os vários termos utilizados para identificar o conhecimento cultural de um cover term. O terceiro elemento da análise de domínio é o simples relacionamento semântico que une os cover terms com todos os included terms.

A concessão de crédito envolve dois domínios: a. concessão com base em garantias; b. concessão com base em confiança. Para efeito desta pesquisa, definiu-se como ambiente ou domínio a concessão de crédito para ERF baseada em relações de confiança, uma vez que essas empresas não dispõem de garantias para oferecer em troca de crédito. Como cover terms desse domínio, optou-se por trabalhar com as categorias crise financeira, empresa em processo de recuperação financeira e seu gestor. Já os included terms que caracterizam os cover terms deverão ser identificados nas entrevistas a partir da relação semântica entre eles. 
Com o objetivo de compreender a predisposição dos gestores credores a confiar em ERF, tendo como foco a concessão de créditos financeiros, foram definidos como sujeitos da pesquisa os gestores de empresas privadas que ocupam cargos executivos com, no mínimo, um ano de experiência e que têm responsabilidade na concessão de crédito para empresas em situação de crise financeira.

Ademais, os executivos que fariam parte dessa amostra seriam de empresas credoras, líderes em seu segmento de atuação de acordo com o critério de faturamento, fornecedoras de matérias-primas para indústrias, instituições financeiras e instituições de fomento mercantil os quais, segundo a experiência dos pesquisadores em processos de recuperação empresarial, são os que mais têm envolvimento com o processo em si. Visando atender ao critério de liderança no segmento de atuação, as empresas foram selecionadas mediante informações adquiridas junto às associações de classe.

A decisão acerca do número de entrevistas foi tomada no decorrer do processo da coleta de dados. Inicialmente, foram realizadas três entrevistas, sendo uma com um executivo de cada tipo de empresas - fornecedora de matéria-prima, instituições financeiras e instituições de fomento mercantil. Ao final dessa rodada, percebeu-se a reiteração de termos e de conhecimentos, os quais surgiram repetidamente numa segunda rodada de entrevistas. As entrevistas, num total de seis, com duração média de 60 minutos, foram gravadas e, posteriormente, transcritas. Tendo em vista a análise dos dados, as entrevistas foram codificadas como: Eı, E2, E3, E4, E5 e E6.

\section{ANÁLISE E INTERPRETAÇÃO dOS RESULTADOS}

\subsection{ANÁLISE DO DOMÍNIO: CONCESSÃO DE CRÉDITO PARA EMPRESAS EM RECUPERAÇÃO FINANCEIRA BASEADA EM RELAÇÕES DE CONFIANÇA}

A análise das entrevistas foi estruturada de forma a, inicialmente, contextualizar o domínio em estudo. Posteriormente, buscou-se caracterizar os cover terms desse domínio - Crise Financeira, Empresa em Recuperação Financeira e Gestores das Empresas em Recuperação Financeira - pela identificação e relação semântica que estes têm com seus respectivos included terms. 
- O PAPEL DA CONFIANÇA NA CONCESSÃO DE CRÉDITO PARA EMPRESAS EM RECUPERAÇÃO • ROGÉRIO SILVEIRA MONTEIRO • MARIA LUISA MENDES TEIXEIRA

\subsection{CONTEXTUALIZAÇÃO DO DOMÍNIO}

A contextualização do domínio da concessão de crédito para ERF baseada em relações de confiança contemplou aspectos relativos aos gestores de crédito em seu ambiente de atuação, uma vez que, em última instância, são eles que decidem favoravelmente ou desfavoravelmente sobre a concessão do crédito.

Embora, em linhas gerais, as análises para concessão de crédito respondem de forma similar para as empresas dos mais diversos segmentos, portes, regiões, para empresas em recuperação financeira, os gestores de crédito entendem que as análises assumem algumas características particulares, pois apresentam aspectos mais "delicados" (EI; E2; E5; E6).

A apreciação das entrevistas possibilitou a identificação dos elementos que expressam a forma de pensar, de sentir e de decidir dos gestores de crédito quanto à viabilidade do negócio. Tais elementos são construídos a partir do acúmulo de conhecimentos e aprendizados adquiridos por meio da sua formação técnica, bem como indicou um dos entrevistados (E5), pela vivência compartilhada, incluindo com colegas de profissão: "grande parte do conhecimento que eu julgo importante para avaliação vem do que você já viu, do que você já passou, já compartilhou”.

Os gestores de crédito declararam que, no exercício de suas responsabilidades, vivem no meio de forças contraditórias. Por um lado, eles têm de avaliar criteriosamente os riscos envolvidos nas transações; por outro, existem as necessidades da empresa de vender, a obrigação de os executivos cumprirem metas cada vez mais agressivas, de superarem a concorrência e as decisões emocionais amparadas em relacionamentos. Essas são algumas razões para que a concessão de crédito seja feita elevando a exposição ao risco (Eı; E2; E4; E5; E6).

É possível compreender que a motivação dos credores para participarem de um processo de recuperação financeira está provavelmente fundamentada em necessidades financeiras e em necessidades sociais.

Sob a óptica financeira, a maioria dos credores reconhece que existe uma preocupação pela recuperação dos seus recursos e, assim, os credores colocam-se disponíveis para conceder novos créditos às ERF de acordo com alguns parâmetros previamente observados.

Pode-se atribuir, ainda, à questão financeira, a busca por parte das empresas credoras em manterem ativos clientes, mesmo que em dificuldade financeira, pois reconhecem a necessidade de suprirem a sua própria geração de faturamento. Isso quer dizer que o credor tem a preocupação na manutenção dos níveis de faturamento de sua empresa e um rigor grande na análise e na concessão de crédito, o que pode levá-lo à perda de clientes e, consequentemente, à perda de faturamento. 
$\mathrm{O}$ atendimento dessas necessidades financeiras, no entanto, assume um caráter delicado ao considerar a percepção adicional do risco que a concessão de créditos a uma empresa em processo de recuperação possui.

O segundo foco de atenção exposto pelos entrevistados quanto à motivação para a concessão de créditos às ERF pode ser entendido como social.

Alguns entrevistados expressaram sua predisposição em ajudar as empresas que estão neste tipo de processo não apenas pelas razões financeiras apresentadas antes, mas também por uma preocupação do impacto social que a falência de uma empresa pode trazer, pela manutenção do nível de emprego, a continuidade da empresa no contexto regional e as suas relações com seus diversos clientes e fornecedores.

Conceder crédito para esses profissionais significa "possibilitar" (E2; E3), "facilitar" (E4), "intensificar" (E2; E5), "ajudar" (EI; E6) as transações entre as empresas.

Tendo em vista os aspectos que envolvem a recuperação financeira de uma empresa, bem como as limitações decorrentes do acesso às garantias, os gestores de créditos reconhecem que a análise e, finalmente, a concessão do crédito financeiro está alicerçada sob relações de confiança.

[E4] Eu acho que a questão do crédito em empresas em dificuldade financeira é uma situação limite. Então o mais importante seria, de fato, a confiança entre as partes, porque a questão de avaliação de dados econômico-financeiros, por si só, fica prejudicada.

[EI] Eu acho que normalmente, e acredito que a maioria das empresas funcione assim, nós restabelecemos o relacionamento e liberamos crédito para uma empresa em crise sob bases de confiança porque o que mais ela pode oferecer? Isso é muito subjetivo, muito delicado.

A confiança apontada pelos entrevistados é decorrente da avaliação que o credor faz da ERF e do gestor dessa empresa: a. a empresa solicitante; b. o gestor dessa empresa: "[E2] olha, para liberar o crédito nós precisamos conhecer a empresa e também seus administradores"; “[EI] é preciso saber se a empresa tem condições econômico-financeira e operacional, assim como se tem gestores competentes para administrá-la".

Para os entrevistados, o crédito é definido pela construção da visão que os gestores de crédito têm da empresa solicitante formada a partir da análise de 
informações e do histórico bem sucedido de transações realizadas. Essas informações referem-se à empresa solicitante e a seus gestores, as quais são analisadas segundo critérios objetivos, tais como "informações contábeis" (E2) colhidas em fontes primárias e secundárias. Essas informações constituem-se em elementos relativos às dimensões de competência e cognitiva mencionadas respectivamente por Das e Teng (200I) e McAllister (I995).

Os respondentes revelaram, entretanto, que as informações oficiais, tais como demonstrativos contábeis e gerenciais fornecidos pelas empresas, são frágeis e algumas vezes não são dignos de confiança, pois podem ser manipuladas: "você vai acreditar somente nos balanços?" (EI); "a contabilidade pode ser manipulada" (E2); "tem aquela piada do contador que pergunta qual o resultado que você quer mostrar" (E5); entre outros exemplos. Dessa forma, para os gestores de crédito, as informações devem ser checadas em outras fontes secundárias como as empresas de análise de crédito e associações de classe.

Tendo em vista a fragilidade das informações oficiais, os gestores credores lançam mão de aspectos subjetivos para embasar suas decisões. É na sua rede de relacionamentos, com outros gestores credores (EI; E2; E3; E4; E5; E6), que eles obtêm impressões sobre a competência e a integridade das organizações solicitantes e de seus gestores, sendo nessas capacidades e nesses profissionais que eles depositam maior confiança (EI; E3).

A partir da leitura das falas dos entrevistados, percebe-se que "no fundo mesmo" (EI) a decisão pela concessão de crédito está depositada nas expectativas positivas que os gestores de crédito têm quanto ao comportamento do outro (LEWICKI, MCALLISTER, BIES, I998; DAS; TENG, 200I), ou seja, baseado na confiança: "[EI] o crédito é concedido baseado na confiança que temos em relação à capacidade daquela empresa honrar seus compromissos. Não só da empresa, mas também dos seus gestores".

Essa confiança é construída a partir do relacionamento decorrente das transações interorganizacionais, porém a "grande chave para criação de relações de confiança duradouras entre as empresas é a transparência (EI)". Confiar é para eles "acreditar" que o outro irá cumprir o compromisso (EI; E2; E5; E6), é verificar "a vontade do empresário em fazer isto" (E6), é "experimentar a relação" (E3).

Além disso, valem-se ainda de outros critérios subjetivos, como as impressões formadas a partir do relacionamento com os gestores das empresas credoras (EI; E2; E3; E4; E5; E6) e o feeling quanto à capacidade deles de honrar com os compromissos assumidos (EI; E4; E5).

$\mathrm{Na}$ visão dos entrevistados, o feeling é um elemento decisivo no processo de avaliação e concessão de crédito financeiro para ERF. O feeling é entendido como uma capacidade de percepção da realidade e do outro, constituída a partir 
das experiências e vivência pessoais e que foge de uma linha lógica e concreta de raciocínio: "[E3] O feeling é o aspecto mais subjetivo que você utiliza. É uma capacidade construída com a experiência. Acertando, errando...”.

O feeling assume um peso significativo nesse processo de estabelecimento de relações de confiança, pois ele depreende da capacidade que se tem de perceber no outro os atributos desejados. Ele está no encantamento estabelecido nas relações entre credores e gestores, ou na sensação que vem da empatia que se tem com o outro. Para os entrevistados, esse feeling tem um peso de $50 \%$ a $75 \%$ no processo de decisão da concessão de créditos financeiros às empresas em recuperação.

Para consolidar a estrutura de análise do domínio definido, optou-se por aprofundar os elementos crise financeira, ERF e os gestores das ERF como cover terms, por ser a partir do conhecimento desses que as relações de confiança são constituídas.

\section{ANÁLISE DO COVER TERM CRISE FINANCEIRA}

Conforme pode ser observado no Quadro I, a crise financeira de uma empresa pode ser motivada por dois aspectos: o interno e/ou o externo. Segundo os entrevistados, compreender os motivos que levaram a empresa a uma situação de crise financeira é um dos primeiros passos para avaliar a concessão de crédito para uma ERF.

Existe a possibilidade de que a crise financeira tenha sido gerada por aspectos externos à organização, como uma situação desfavorável no mercado de atuação da empresa, o que provavelmente provocará uma crise setorial.

Sob a óptica dos aspectos internos à organização, porém, pode-se inferir que uma empresa, ao entrar em crise financeira, é vítima de suas próprias ineficiências, que foram originalmente provocadas por aqueles que deveriam ser os norteadores das suas estratégias de sucesso e os condutores da organização - os gestores.

Uma empresa pode entrar em crise financeira por uma falta de visão dos seus administradores, pela falta de preparo do administrador, pela ausência de instrumentos de gestão, tais como controles, planejamentos, treinamentos de equipes, pela prática de políticas administrativas tipicamente familiares, o que significa, à luz dos entrevistados, uma gestão voltada à priorização de benefícios para a família, em detrimento da organização (E1; E2; E3; E4; E5; E6); “[E5] Para grande maioria das empresas que eu vi até hoje entrar em crise, primeiro é a falta de visão dos administradores".

Ainda mais, existem algumas citações referentes à fraude do administrador, porém sempre associadas à falta de instrumentos de controle e gestão (E2; E4; E5). 
- O PAPEL DA CONFIANÇA NA CONCESSÃO DE CRÉDITO PARA EMPRESAS EM RECUPERAÇÃO • ROGÉRIO SILVEIRA MONTEIRO • MARIA LUISA MENDES TEIXEIRA

\section{QUADRO I}

ANÁLISE DO COVER TERM CRISE FINANCEIRA

DOMÍNIO

\begin{tabular}{|c|c|c|c|c|}
\hline \multicolumn{5}{|c|}{ CONCESSÃO DE CRÉDITO PARA ERF BASEADA EM RELAÇÕES DE CONFIANÇA } \\
\hline \multicolumn{2}{|c|}{ INCLUDED TERMS } & \multirow{2}{*}{$\begin{array}{c}\text { TIPO } \\
E\end{array}$} & RELAÇÃO & COVER \\
\hline - Problemas no segmen & o atuação & & \multirow{7}{*}{ É razão para } & \multirow{7}{*}{$\begin{array}{c}\text { Crise } \\
\text { financeira }\end{array}$} \\
\hline $\begin{array}{l}\text { - Falta de visão dos } \\
\text { administradores }\end{array}$ & $\begin{array}{l}\text { - Falta de preparo dos } \\
\text { administradores }\end{array}$ & \multirow{6}{*}{ I } & & \\
\hline $\begin{array}{l}\text { - Gestão tipicamente } \\
\text { familiar }\end{array}$ & $\begin{array}{l}\text { - Fraude do } \\
\text { administrador }\end{array}$ & & & \\
\hline - Falta de controle & - Falta de planejamento & & & \\
\hline $\begin{array}{l}\text { - Falta de equipe } \\
\text { qualificada }\end{array}$ & $\begin{array}{l}\text { - Falta de } \\
\text { profissionalismo }\end{array}$ & & & \\
\hline - Má gestão (acionista) & $\begin{array}{l}\text { - Vício de emitir } \\
\text { cheques }\end{array}$ & & & \\
\hline $\begin{array}{l}\text { - Questões } \\
\text { comportamentais }\end{array}$ & - Questões estruturais & & & \\
\hline
\end{tabular}

Tipo E - externo; Tipo I - interno.

Fonte: Dados da pesquisa.

Uma vez identificados os motivos que levaram a empresa a uma crise financeira, a análise e a concessão de créditos financeiros para empresas em recuperação exigem por parte do gestor de crédito a verificação quanto às reais condições da empresa para uma recuperação, ou melhor, quanto à existência de viabilidade no negócio.

A viabilidade do negócio é avaliada pelos entrevistados a partir de um conjunto de recursos, de características e, por que não considerar os atributos da empresa, bem como das oportunidades e das ameaças existentes no mercado em que ela está inserida. Esses atributos são das mais diversas naturezas. 


\subsection{ANÁLISE DO COVER TERM EMPRESA EM RECUPERAÇÃO FINANCEIRA}

A análise do cover term ERF ocorreu mediante a identificação de seus included terms e as relações semânticas com eles estabelecidas, as quais se apresentam sintetizadas no Quadro 2.

\section{QUADRO 2}

ANÁLISE DO COVER TERM EMPRESA

EM RECUPERAÇÃO FINANCEIRA

\begin{tabular}{|c|c|c|c|c|}
\hline \multicolumn{5}{|c|}{ DOMÍNIO } \\
\hline \multicolumn{5}{|c|}{ CONCESSÃO DE CRÉDITO PARA ERF BASEADA EM RELAÇÕES DE CONFIANÇA } \\
\hline INCLU & TERMS & TIPO & $\begin{array}{c}\text { RELAÇÃO } \\
\text { SEMÂNTICA }\end{array}$ & COVER TERMS \\
\hline $\begin{array}{l}\text { - Nível da } \\
\text { rentabilidade } \\
\text { - Capacidade } \\
\text { tecnológica } \\
\text { - Estrutura física } \\
\text { - Disponibilidade } \\
\text { demão-de-obra }\end{array}$ & $\begin{array}{l}\text { - Tem que dar lucro } \\
\text { - Equipamentos } \\
\text { produtivos } \\
\text { - Níveis de estoque }\end{array}$ & Comp. & & \\
\hline $\begin{array}{l}\text { - Boa imagem no } \\
\text { mercado } \\
\text { - Imagem da } \\
\text { empresa na } \\
\text { comunidade } \\
\text { - Reputação } \\
\text { - Ser competente } \\
\text { - Modelo de gestão }\end{array}$ & $\begin{array}{l}\text { - Práticas leais de } \\
\text { mercado } \\
\text { - Seriedade } \\
\text { - História da empresa } \\
\text { - Ser competitiva } \\
\text { - Qualidade da } \\
\text { gestão }\end{array}$ & 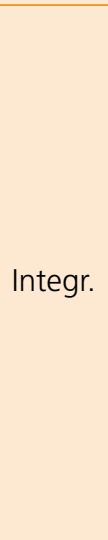 & $\begin{array}{c}\text { São atributos } \\
\text { da }\end{array}$ & $\begin{array}{c}\text { Empresa em } \\
\text { Recuperação } \\
\text { Financeira }\end{array}$ \\
\hline
\end{tabular}


- O PAPEL DA CONFIANÇA NA CONCESSÃO DE CRÉDITO PARA EMPRESAS EM RECUPERAÇÃO • ROGÉRIO SILVEIRA MONTEIRO • MARIA LUISA MENDES TEIXEIRA

\section{QUADRO 2 (CONTINUAÇÃO)}

ANÁLISE DO COVER TERM EMPRESA

EM RECUPERAÇÃO FINANCEIRA

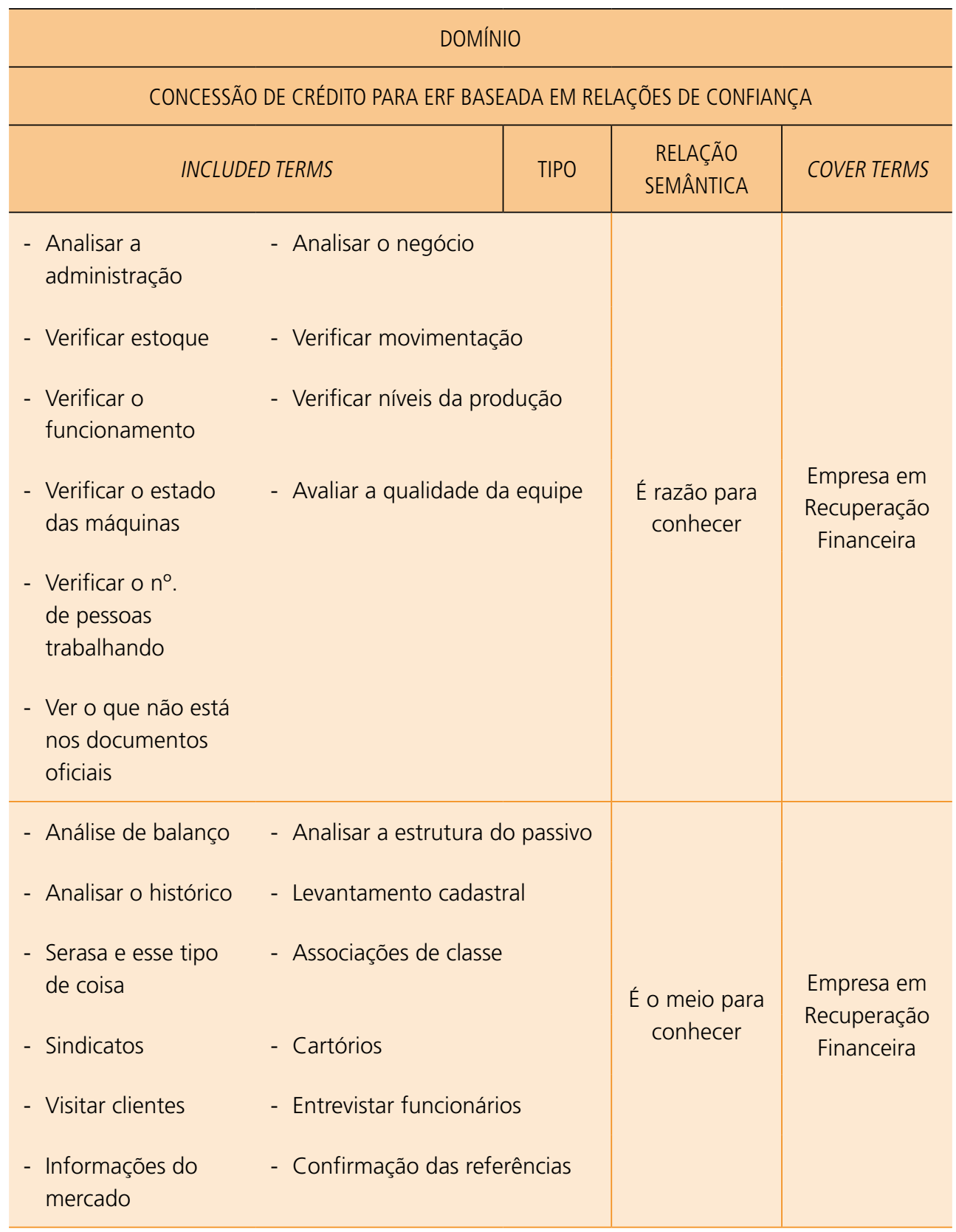




\section{QuAdro 2 (CONTINUAÇÃO)}

ANÁLISE DO COVER TERM EMPRESA

EM RECUPERAÇÃO FINANCEIRA

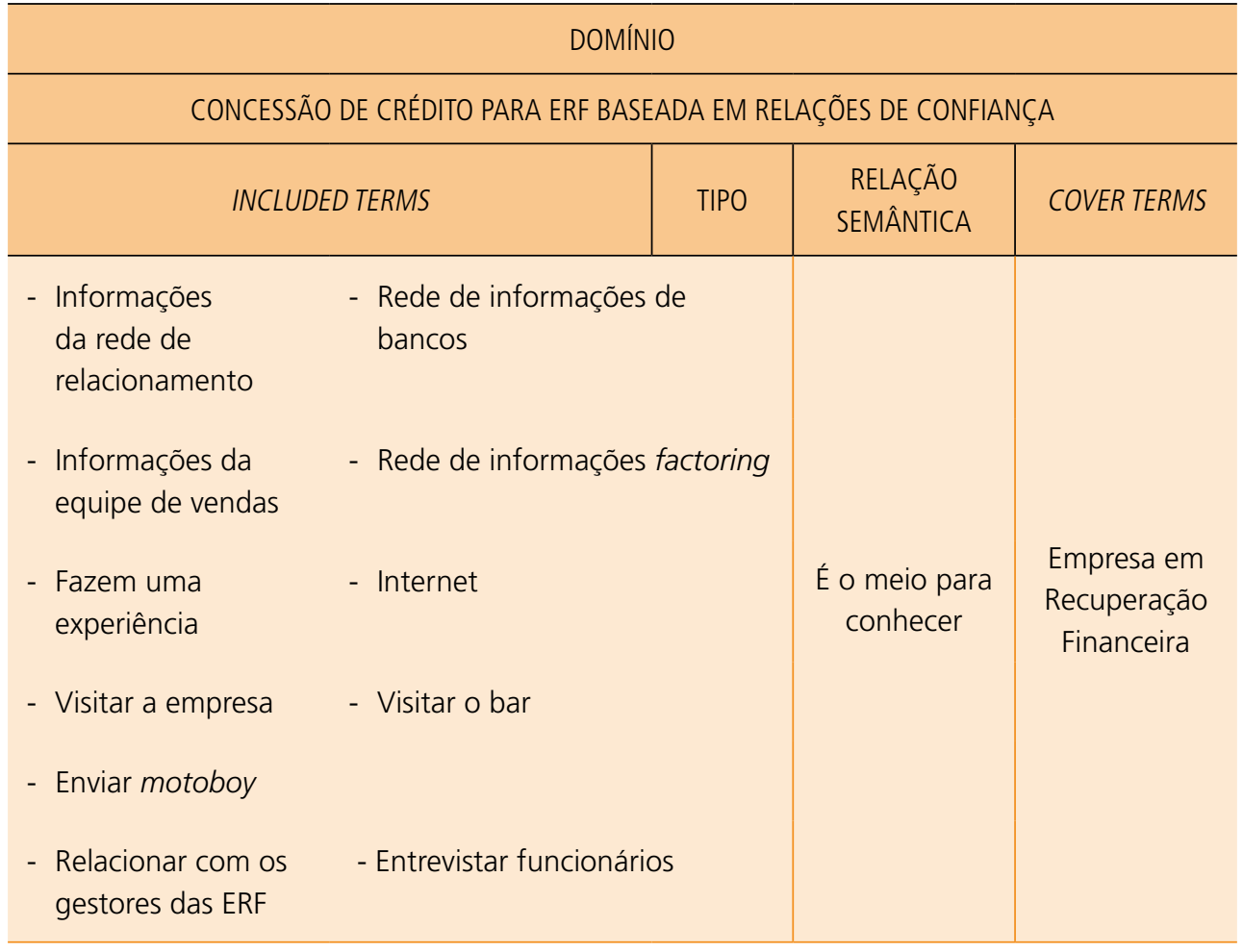

Comp.: Competência; Integr.: Integridade.

Fonte: Dados da pesquisa.

\subsection{ATRIBUTOS DA ERF}

Inicialmente, o credor procura levantar um conjunto de informações que lhe permita "tirar uma fotografia" (E3) do comprometimento financeiro da empresa. Essas informações têm como fonte a própria empresa a partir de dados contábeis e financeiros, bem como os agentes externos à organização, tais como instituições de crédito (Serasa), instituições financeiras (bancos e factorings), fornecedores, clientes, cartórios, entre outros. Com isso, espera-se levantar a gravidade da situação: “[E2] Qual é o tamanho do problema que ela tem? Como está o patrimônio dela? Ela consegue saldar isso [as dívidas]. Não consegue?”. 
De posse da fotografia, os credores passam a preocupar-se com a capacidade de pagamento que a empresa em recuperação apresenta, ou seja, com o nível de rentabilidade alcançado pela empresa que deverá servir para viabilizar a operação atual e, ainda, amortizar o endividamento passado.

A empresa em recuperação também deve apresentar recursos não-financeiros suficientes para sua normalidade operacional. Esses recursos a serem considerados são: o nível da capacidade tecnológica, os equipamentos produtivos adequados, a estrutura física da empresa e da matéria-prima, a disponibilidade de mão-de-obra, entre outros: "[E4] Ao analisarmos uma empresa também esperamos encontrar recursos não financeiros [...]. São os equipamentos, a tecnologia, a estrutura e também a qualidade da mão-de-obra".

Outra característica "não-financeira" citada como importante é a reputação que a ERF tem no mercado, reconhecida pela "história da empresa” (EI; E3; E6), que atesta sua tradição nas boas práticas comerciais e na adequada conduta no relacionamento com fornecedores, clientes, colaboradores e comunidade.

[EI] Preferimos empresas que tenham uma boa imagem no mercado quanto às suas práticas honestas e legais. Se elas respeitam as boas práticas comerciais devem ser respeitadas por seus clientes e concorrentes. E também se elas são respeitadas na sua comunidade. Como falei, se onde elas estão inseridas, elas são respeitadas por aquilo que fazem. Existe uma boa conduta com relação aos seus colaboradores?

Os entrevistados afirmam que a confiança necessária para a concessão de créditos a uma empresa em recuperação também é sustentada a partir da forma pela qual a organização é administrada e que é entendida por eles como o conjunto de normas, de processos e de políticas adotado pela empresa e sua adequação às expectativas dos entrevistados, bem como pela presença de uma visão clara dos rumos estratégicos da empresa.

\subsection{MEIOS PARA CONHECER A ERF}

A análise das entrevistas permitiu conhecer quatro meios distintos utilizados pelos entrevistados. São eles: a. informações oferecidas pela empresa; b. informações colhidas em uma rede de relacionamentos; c. entrevistas nas empresas; d. relacionamento com os gestores das ERF.

Genericamente, para conhecê-las, os entrevistados buscam centrar suas análises nas informações oficiais divulgadas sobre a empresa, tais como balanços e 
demonstrativos financeiros, a fim de obter um perfil do nível de comprometimento financeiro, bem como verificar sua capacidade de pagamentos.

Os entrevistados declararam, no entanto, que não reconhecem como confiáveis as informações oriundas da própria empresa, uma vez que podem ser suscetíveis a qualquer tipo de manipulação.

[E2] Hoje, eu acho que hoje os instrumentos que você tem disponível para análise de crédito são muito escassos. Por exemplo, você vai confiar num balanço? Balanço a gente sabe que tem "N" maneiras de você... Tem empresas que alteram, às vezes, o balanço. Então, balanço, muitas vezes, nem sempre, é medida confiável e é uma fotografia da empresa.

Por isso, a análise objetiva de crédito torna-se um pouco mais segura quando a situação financeira da empresa e de seus demais atributos é verificada no mercado, a partir da rede de relacionamento dos credores: "[EI] O que realmente importa são as referências colhidas na rede de relacionamentos. Estas são as mais verdadeiras. Estas informações dizem respeito à normalidade ou não da empresa consultada".

Essa rede de relacionamento é composta por fornecedores, bancos, factorings, clientes e instituições fornecedoras de informações cadastrais, os quais são acionados para o levantamento da situação financeira da empresa - níveis de endividamento, confiabilidade das operações, pagamentos em cartórios, pedidos de falência, cumprimento dos compromissos assumidos -, bem como aspectos não-financeiros relacionados à sua imagem ou à sua reputação.

Se, entretanto, o volume de crédito for maior, os entrevistados afirmaram que se tornam fundamentais as visitas às empresas. Tais visitas têm como objetivo validar as informações financeiras oferecidas pela empresa, bem como aquelas colhidas pela rede de relacionamentos. Além disso, as visitas servem para verificar a estrutura produtiva e tecnológica da empresa e a sua normalidade operacional.

Os entrevistados expuseram que, algumas vezes, utilizam meios mais informais de coleta de informações acerca da empresa e sobre os gestores, especialmente quando se tem algum tipo de desconfiança quanto às informações sobre a corporação e/ou seus gestores. Esses meios podem ser exemplificados como visita ao bar ao lado da empresa para conversar com os funcionários, envio de motoboy com a finalidade de verificar a movimentação de entrada e saída de caminhões, contratação de profissionais que fotografam a empresa, entre outros. Para tanto, transcreve-se a fala de um dos entrevistados: 
- O PAPEL DA CONFIANÇA NA CONCESSÃO DE CRÉDITO PARA EMPRESAS EM RECUPERAÇÃO • ROGÉRIO SILVEIRA MONTEIRO • MARIA LUISA MENDES TEIXEIRA

[E3] Quando achamos algo suspeito, mandamos um representante no bar ao lado da empresa para bebericar com os funcionários e retirar informações sobre a empresa. Informaç̃es como se a produção está normal, se os salários estão atrasados etc.

\subsection{ANÁLISE DO COVER TERM GESTOR DA EMPRESA EM RECUPERAÇÃO FINANCEIRA}

De acordo com os entrevistados, os gestores de uma empresa em recuperação são os administradores, donos, empresários ou mesmo os gestores que lideram o processo de recuperação financeira da empresa.

De um modo geral, os entrevistados apontaram preferências quanto a atributos específicos dos gestores necessários para a predisposição a confiar em ERF, como pode ser observado no Quadro 3.

A avaliação do gestor de empresas em recuperação está focada em três conjuntos de atributos claramente definidos: a. performance; b. credenciais; c. aspectos comportamentais ou de cidadania.

Sob os aspectos performance e credenciais, espera-se do gestor de uma ERF que ele tenha "capacidade e qualidade" (E2; E5; E6). Essas características estão sustentadas por um conjunto de vivências bem-sucedidas que asseguram ao mercado que esse profissional tem tanto experiência como know-how para a condução de um processo de recuperação financeira. Para os entrevistados, a qualidade do gestor é associada à sua eficiência comprovada pelos casos de sucesso já implementados.

Tanto a capacidade como a qualidade dos gestores pode ser, de alguma forma, vinculada aos atributos de competência, eficiência e eficácia comentados pelos entrevistados. $\mathrm{O}$ aspecto da competência aparece associado à capacidade do gestor na condução do negócio, às suas habilidades técnicas e às suas atitudes firmes na gestão da organização. Já os aspectos de eficiência e eficácia aparecem quando eles atribuem uma importância grande às realizações bem-sucedidas dos gestores: "[E5] Justamente a capacidade, as habilidades que esses administradores têm, não só a capacidade técnica ou acadêmica, mas simplesmente conhecer o negócio que eles estão inseridos".

Espera-se também que os gestores tenham o conhecimento do negócio que eles estão inseridos, além de formação acadêmica, pois esses atributos são entendidos como um diferencial importante para a consolidação de sua capacidade técnica na condução dos negócios. A condução dos negócios deve, então, ser desenvolvida por "pessoas de alto nível” (EI). 
Sob os aspectos comportamentais, de integridade do gestor, os entrevistados (EI; E3; E6) esperam que o gestor tenha claramente definido sua intenção em preservar a atividade da empresa, bem como sua predisposição a fazer os sacrifícios necessários para levar adiante a recuperação financeira da organização: “[E6] A questão do crédito para empresas em dificuldades financeiras [...] é uma questão de confiança [...] que depende de avaliar se o trabalho é realmente para preservar a atividade da empresa".

Com o objetivo de buscar aliados ao processo, o gestor da ERF deve atuar de forma a encantar os envolvidos. Essa capacidade de "encantamento pessoal" (E4) é manifestada por uma "postura um pouco de igualdade" (E4) do gestor perante os agentes internos e externos da organização. Assim, mostrará que não há privilegiados neste processo e que não serão admitidos comportamentos oportunísticos:

[E4] O gestor tem que estar [sic] posicionado quando se fala em empresa em dificuldade [...] tendo uma postura um pouco de igualdade, porque isso é muito importante e eu acho que isso determina aí [sic] uma posição de encantamento e de confiança, está certo?

A avaliação de crédito financeiro de uma empresa em recuperação, entretanto, não terá efeito se não vier acompanhada da percepção por parte dos credores da reputação do gestor. Essa reputação é reconhecida pelo credor a partir das referências que o gestor dispõe no mercado e da interação entre as partes. Valoriza-se, nesse momento, o caráter do gestor, associando-o à sua honestidade, a uma postura verdadeira e equilibrada.

Esse caráter é percebido por meio da normalidade e idoneidade das operações. Assim, a credibilidade que o gestor inspira é "conquistada com o dia-a-dia, com os objetivos sendo cumpridos” (E6): “[E6] Só que a questão de caráter é credibilidade. E a credibilidade você vai conquistando. Você vai conquistando com o dia-a-dia, com os objetivos sendo cumpridos, enfim". 
- O PAPEL DA CONFIANÇA NA CONCESSÃO DE CRÉDITO PARA EMPRESAS EM RECUPERAÇÃO • ROGÉRIO SILVEIRA MONTEIRO • MARIA LUISA MENDES TEIXEIRA

\section{QUADRO 3}

\section{ANÁLISE DO COVER TERM GESTOR DA EMPRESA EM RECUPERAÇÃO FINANCEIRA}

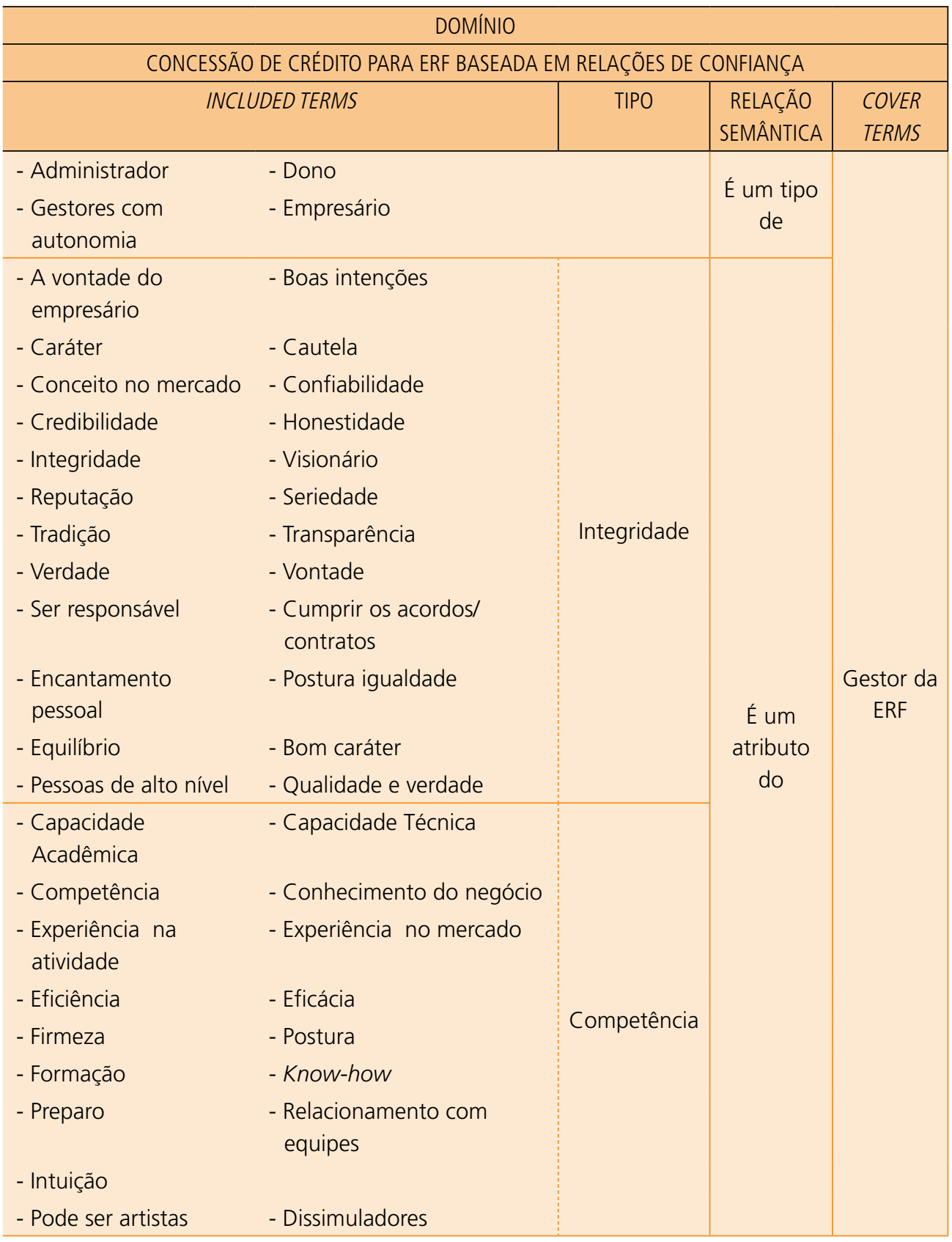




\section{QUADRO 3 (CONTINUAÇÃO)}

ANÁLISE DO COVER TERM GESTOR DA EMPRESA EM RECUPERAÇÃO FINANCEIRA

\begin{tabular}{|c|c|c|c|c|}
\hline \multicolumn{5}{|c|}{ DOMÍNIO } \\
\hline \multicolumn{5}{|c|}{ CONCESSÃO DE CRÉDITO PARA ERF BASEADA EM RELAÇÕES DE CONFIANÇA } \\
\hline \multicolumn{2}{|c|}{ INCLUDED TERMS } & TIPO & $\begin{array}{c}\text { RELAÇÃO } \\
\text { SEMÂNTICA }\end{array}$ & $\begin{array}{l}\text { COVER } \\
\text { TERMS }\end{array}$ \\
\hline $\begin{array}{l}\text { - Explorar a visão deles } \\
\text { do negócio } \\
\text { - Verificar a situação do } \\
\text { mercado } \\
\text { - Conhecer a pessoa }\end{array}$ & $\begin{array}{l}\text { - Estabelecer compromissos } \\
\text { - Desenvolver a relação }\end{array}$ & & $\begin{array}{l}\text { É razão } \\
\text { para } \\
\text { conhecer }\end{array}$ & \\
\hline $\begin{array}{l}\text { - Visitar o gestor } \\
\text { - Consultar rede de } \\
\text { informações } \\
\text { - Enviar motoboy } \\
\text { - Contato pessoal } \\
\text { - Entrevistar } \\
\text { funcionários }\end{array}$ & $\begin{array}{l}\text { - Estabelecer relacionamentos } \\
\text { - Visitar o bar } \\
\text { - Visitar clientes }\end{array}$ & & $\begin{array}{l}\text { É o meio } \\
\text { para } \\
\text { conhecer }\end{array}$ & $\begin{array}{c}\text { Gestor da } \\
\text { ERF }\end{array}$ \\
\hline
\end{tabular}

Fonte: Dados da pesquisa.

Já o caráter do gestor é questionado não por um acidente de percurso, mas quando eventuais insucessos são decorrentes de ações de má fé, ou ainda, quando se percebe que ele age como "artista" (E3), ou seja, se ele está dissimulando e tentando passar uma visão errônea sobre a situação da empresa.

Por isso, acredita-se que o gestor tenha uma postura verdadeira ante a situação da empresa. A verdade é percebida pela seriedade e pela transparência utilizada pelo gestor no relacionamento com o credor. O posicionamento dos gestores deve ser claro e objetivo quanto à situação da empresa e não um comportamento de "enfeitar o peru" (E2), mencionando ou enaltecendo atributos da empresa ou pessoais que não existem: "[E2] Você conversa com o administrador, ele é transparente? O que ele te passa? Como é a forma como ele negocia com você? Então essa questão da transparência, questão da seriedade dos gestores é muito importante para nós".

A conduta de seriedade e transparência do gestor é reforçada pela responsabilidade com a qual ele conduz os negócios. A responsabilidade está presente quando "o que fala, cumpre; o que fala, cumpre" (E6). 
- O PAPEL DA CONFIANÇA NA CONCESSÃO DE CRÉDITO PARA EMPRESAS EM RECUPERAÇÃO • ROGÉRIO SILVEIRA MONTEIRO • MARIA LUISA MENDES TEIXEIRA

Finalmente, essas decisões técnicas são fundamentadas a partir de uma visão estratégica do negócio que conduzirá a um processo de mudança da organização.

[E3] Na verdade, uma empresa em dificuldade, talvez o que ela menos precise é de recursos financeiros. Uma empresa em dificuldade precisa de mudança de gestão organizacional e, muitas vezes, até trocar o administrador, pois, para resolver o problema, é como largar de fumar ou beber, é quase um vício parecido: largar de emitir cheques.

\subsection{MEIOS PARA CONHECER OS GESTORES DE ERF}

Quando se buscam identificar os aspectos do gestor via rede de relacionamentos, os credores tentam verificar como ele é percebido no mercado, especialmente em relação aos aspectos de integridade e da competência. No entanto, as visitas às ERF assumem uma finalidade mais importante que é a de estabelecer o relacionamento com os gestores da empresa, em que buscam identificar os atributos desses gestores e se eles atendem às expectativas desejáveis para a concessão de créditos financeiros.

O relacionamento entre o credor e o gestor da ERF é entendido como primordial para o estabelecimento das relações de confiança. Para os entrevistados, o contato pessoal é importante, pois, nesse momento, é que se possibilita conhecer as pessoas, estabelecer compromissos e acompanhar o desenvolvimento das relações entre as partes: "[E5] [...] mas sem dúvida nenhuma o aspecto mais importante é aquele tal negócio do contato por contato. Às vezes, um contato de 30 minutos, 60 minutos, 90 minutos, você tem uma noção geral da pessoa".

\subsection{INTERPRETAÇÃO E DISCUSSÃO DOS RESULTADOS}

Os resultados evidenciaram que a partir das experiências vivenciadas na concessão de crédito para ERF, e no aprendizado compartilhado com os colegas de profissão, os gestores credores desenvolveram símbolos que lhes permitem identificar indícios de que as ERF e seus gestores podem ser ou não merecedores da sua confiança. Esses símbolos são representados pelos atributos das ERF e seus gestores, possibilitando ser classificados pelos mesmos critérios empregados por Das e Teng (200I) e McAllister (I995).

Os atributos das ERF citados pelos gestores podem ser classificados como de integridade e competência. 
Para eles, uma ERF digna de confiança é aquela que tem uma reputação reconhecida pela boa imagem que tem no mercado e na comunidade em que está inserida quanto à seriedade de suas ações, às práticas leais de mercado, à qualidade da sua gestão, sendo todas comprovadas pela sua história. Esses aspectos podem ser considerados aspectos de integridade. Já os aspectos de competência podem ser observados pelas citações de atributos que caracterizam a ERF quanto à sua competência organizacional aferidas no seu modelo de gestão, na sua estrutura organizacional, na capacidade tecnológica, na qualidade dos equipamentos produtivos, na disponibilidade de mão-de-obra, com os quais buscam assegurar sua competitividade no mercado. Esses aspectos de integridade e competência das ERF são, para Das e Teng (200I), elementos que dão sustentação às relações construídas com base na confiança e delineiam, respectivamente, as intenções da empresa e a sua capacidade de realização.

Ao observar os gestores das ERF, os gestores credores buscam também identificar neles um conjunto de atributos que lhes permitam reconhecê-los como um par profissional confiável. Os atributos citados pelos entrevistados evidenciaram a performance e as credenciais, assim como o comportamento de cidadania dos gestores das ERF. Esses atributos são, para McAllister (I995), antecedentes das relações de confiança.

Para os entrevistados, o gestor das ERF age de forma a demonstrar suas boas intenções quanto à recuperação da empresa pela sua competência em geri-la de forma eficiente e eficaz. Essa competência é percebida a partir de uma postura firme na vontade de encontrar de soluções sustentadas pela experiência na atividade e no mercado e pelo comportamento sério e responsável no cumprimento dos acordos - atributos de performance. Ademais, sua imagem é consolidada pelas credencias acadêmicas e técnicas, assim como, o know-how necessário para esta atividade, conferindo uma imagem de profissional de alto nível.

Adicionalmente, o gestor das ERF é percebido a partir de comportamentos que evidenciam sua reputação consolidada pela credibilidade, confiabilidade e integridade reconhecidas no mercado. Seu bom caráter, sua honestidade, a transparência, a qualidade e sua postura de igualdade revestem-no de um encantamento pessoal que facilita a construção de laços emocionais sustentados por sentimentos recíprocos - comportamento de cidadania. Tais laços são construídos a partir dos relacionamentos estabelecidos entre as partes e intensificados pela frequência de interações.

Os atributos percebidos dos gestores das ERF por parte dos gestores de crédito possibilitam a construção das relações de confiança, com exceção àqueles em que o gestor é percebido como um artista que se utilizam de dissimulações, buscando "enfeitar o peru". 
- O PAPEL DA CONFIANÇA NA CONCESSÃO DE CRÉDITO PARA EMPRESAS EM RECUPERAÇÃO • ROGÉRIO SILVEIRA MONTEIRO • MARIA LUISA MENDES TEIXEIRA

Conforme proposto por McAllister (I995), os atributos de performance e as credenciais são elementos que antecedem a dimensão cognitiva das relações de confiança; já a frequência das interações e o comportamento de cidadania fortalecem a construção da confiança afetiva.

As falas dos entrevistados também apresentaram elementos culturais quanto aos meios utilizados pelos gestores credores para conhecerem as ERF e seus gestores, ao se utilizarem de procedimentos não convencionais, os quais se tornaram típicos da atividade de concessão de crédito, como escutar e sondar empregados em ambientes informais sobre aspectos relativos às ERF.

Esses meios evidenciaram a fragilidade da credibilidade das informações inerentes tanto no que se refere às fontes oficiais, quanto às informais, ou seja, os meios utilizados não minimizam a fragilidade das informações e, portanto, não esgotam o risco.

Dessa forma, os gestores credores ao decidirem pela concessão de créditos às ERF valem-se das suas expectativas positivas em relação ao comportamento do outro (LEWICKI; McALLISTER; BIES, I998; DAS; TENG, 200I) e revelam sua disposição por assumir o risco potencial (MAYER; DAVIS; SCHOORMAN, I995), evidenciando que a concessão passa a ser baseada em relações de confiança.

\section{CONCLUSÕES}

Os resultados da pesquisa permitiram compreender a predisposição dos gestores de empresas credoras a confiar em ERF, tendo em vista a concessão de créditos financeiros destinados a essas empresas, objetivo proposto para este trabalho. Essa predisposição é construída a partir de elementos objetivos e subjetivos presentes nas referidas empresas e em seus gestores, corroborando as proposições de Das e Teng (200I) e McAllister (I995).

Esses elementos, mediante vivência e aprendizado adquirido na experiência de concessão de crédito e compartilhado com colegas de profissão, tornaram-se símbolos com significados a ele associados mediante os quais os gestores credores avaliam se as ERF e/ou seus gestores são merecedores de confiança. Esses símbolos podem ser classificados conforme as dimensões propostas por Das e Teng (200I) e McAllister (I995). Assim sendo, os símbolos que trazem ser as ERF merecedoras de confiança dizem respeito à sua competência e à sua integridade, enquanto aqueles que indicam serem os gestores das ERF, confiáveis, são relativos à confiança cognitiva e afetiva.

Ao se tornarem símbolos com significado compartilhado por uma coletividade, no caso, os gestores credores, adquirem conteúdo cultural, indicando 
que o fenômeno da predisposição a confiar somente pode ser compreendido se analisado, considerando o contexto em que as empresas e gestores implicados se inserem. Em outro sentido, esse resultado chama a atenção para a natureza cultural da confiança, além da social e psicológica, já amplamente discutida pela literatura.

A natureza cultural da predisposição a confiar identificada neste estudo desperta também a atenção para as abordagens metodológicas mais adequadas do fenômeno. A análise de domínio de acordo com os procedimentos propostos por Spradley (I979) mostrou-se, neste trabalho, uma abordagem adequada, que possibilitou a identificação e a análise dos símbolos (folk terms) e das relações destes com outros elementos (cover terms) inerentes à predisposição a confiar.

Além dos símbolos, este estudo revelou que a predisposição a confiar dos gestores credores pesquisados nas ERF está associada a um personagem chave - o gestor das ERF. Não basta que as ERF solicitantes do crédito tenham a elas associados símbolos de integridade e competência, é necessário que os gestores tenham a eles associados símbolos que indiquem performance, credenciais profissionais, comportamento de cidadania e frequência de relações que os indiciem como merecedores de confiança. O gestor da ERF surgiu como principal elemento redutor da incerteza quanto ao risco de conceder crédito.

A importância dos gestores das ERF para a predisposição dos gestores credores a confiar deve-se ao fato da incerteza inerente quanto à confiabilidade das informações oficiais da empresa e porque, em última instância, são eles que vão colocar em execução o plano de recuperação financeira. Uma das implicações deste resultado diz respeito à formação de profissionais capazes de colocar em prática e gerenciar o referido plano. Isto é, não basta que a nova lei de falência preveja a necessidade de elaboração de um plano de recuperação financeira, é necessário que as ERF disponham de profissionais capazes de realizá-lo e que tenham credenciais (atributos) objetivas e subjetivas que eliciem dos gestores credores a predisposição a confiar, tendo em vista a concessão de crédito. Como propõe Luhmann (I996) e outros pesquisadores, de acordo com os resultados encontrados, o plano racional de recuperação financeira não é suficiente para reduzir a incerteza quanto à concessão de crédito.

A relação entre gestores credores e a ERF é permeada pela dúvida potencial mencionada por Lewis e Weigert (I985) e pela complexidade quer decorrente de fatores externos quanto internos à empresa, que a levaram à crise financeira, dificultando a sua recuperação. Segundo esses autores, a redução da complexidade se dá pela criação de um sistema social menos complexo que o existente no ambiente. Os resultados mostram que os gestores credores desenvolveram um sistema de relações sociais, entre si, capaz de construir símbolos e se prestar à 
troca de informações de modo a reduzir não só a incerteza relativa à concessão do crédito, mas também a complexidade que a envolve.

Por sua vez, a confiança surgiu como elemento fundamental para a redução do risco da concessão de crédito, minimizando a incerteza e a complexidade que envolve a relação entre credores e ERF.

Por último, o feeling foi apontado pelos gestores credores como principal elemento decisor da concessão de crédito, desenvolvido ao longo da experiência com a atividade.

Este trabalho evidenciou características simbólicas presentes em um grupo de profissionais: os gestores de crédito. Tais evidências sugerem a presença da natureza cultural da predisposição a confiar e remete para a necessidade do aprofundamento dessa análise levando-se em consideração um número maior de profissionais e, em especial, a diversidade cultural do nosso país em suas regiões geográficas.

\section{REFERÊNCIAS}

ASTRAUSKAS, F. B. Planejamento estratégico para empresas concordatárias e em recuperação judicial. São Paulo, 2003. Dissertação (Mestrado em Administração)-Faculdade de Economia e Administração, Universidade de São Paulo.

BACHMANN, R. Trust, power and control in trans-organizational relations. Organization Studies, v. 22, n. 2, p. 337-365, 200 I.

CASTELLS, M. A sociedade em rede. São Paulo: Paz e Terra, I999.

DAS T. K.; TENG, B.-S. Trust, control, and risk in strategic alliances: an integrated framework. Organization Studies, v. 22, n. 2, p. 25I-283, $200 \mathrm{I}$.

DE MASI, D. A sociedade pós-industrial. São Paulo: Senac, 2000.

GAMBETTA, D. Can we trust trust? In: __. Trust: making and breaking cooperative relations. New York: Basil Blackwell, I988. cap. I2, p. 213-235.

KNIGHT, F. H. Risk, uncertainty and profit. Washington, DC: Beard Books, 2002.

LEWICKI, R. J.; McALLISTER, D. J.; BIES, R. J. Trust and distrust: new relationships and realities. The Academy of Management Review, v. 23, p. 3, jul. 1998.

LEWIS, J. D.; WEIGERT, A. Trust as a social reality. Social Forces, v. 63, n. 4, p. 967-985, jun. I985.

LUHMANN, N. Familiarity, confidence, trust: problems and alternatives. In: GAMBETTA, D. Trust: making and breaking cooperative relations. New York: Basil Blackwell, I988. cap. 6, p. 94-Io8. Social system. California: Stanford University Press, I995.

Confianza. S. 1.: Pontifícia Universidade Católica do Chile, I996.

MAYER, R. C., DAVIS, J. H., SCHOORMAN, F. D. An integration model of organizational trust. The Academy of Management Review, v. 20, n. 3, p. 709-734, jul. I995.

McALLISTER, D. J. Affect - and Cognition - Based Trust as Fundations for Interpersonal Cooperation in Organizations. Academy of Management Journal, v. 38, n. I, p. 24-59, I995. 
MONTEIRO, R. S. Predisposição a confiar em empresas em recuperação financeira: a influência das crenças relativas a organizações e valores dos gestores credores. São Paulo, 2005. Dissertação (Mestrado em Administração)-Centro de Ciências Sociais e Aplicadas, Universidade Presbiteriana Mackenzie.

O plano de recuperação judicial: a responsabilidade vai além dos limites de mero instrumento jurídico. Gazeta Mercantil, São Paulo, I4 de março de 2006. Caderno de Opiniões. p. 3.

NAHM, A. Y.; VONDEREMBSE, M. A. Theory development: an industrial/post-industrial perspective on manufacturing. International Journal of Production Research, v. 40, n. 9, p. 2067-2095, 2002.

PASSUELLO, C. B.; SOUZA, Y. S. Confiança e risco em decisões estratégicas: uma análise de elementos do sistema experiencial. In: Anais... 30 $30^{\circ}$ ENANPAD: 23 a 27 de setembro 2006 - Salvador/BA-Brasil.

SHEPPARD, B. H. Negotiating in long-term mutually interdependent relationships among relative equals. Research on negotiation in organizations, v. 5, p. 3-44, I995.

SPRADLEY, J. The ethnographic interview. New York: Holt, Rinehart and Winston Inc., I979.

WILLIAMSON, O. E. Calculativeness, trust, and economic organization. Journal of Law \& Economics, v. 36, p. 453-486, apr. I993. 